\title{
Multidisciplinary Treatments, Patient Characteristics, Context of Care, and Adverse Incidents in Older, Hospitalized Adults
}

\author{
Leah L. Shever ${ }^{1}$ and Marita G. Titler ${ }^{2}$ \\ ${ }^{1}$ Nursing Research, Quality, and Innovation, University of Michigan Health System, \\ 300 North Ingalls, Room NI 5A07, Ann Arbor, MI 48109-5446, USA \\ ${ }^{2}$ University of Michigan School of Nursing and University of Michigan Health System, \\ 400 North Ingalls, Suite 4170, Ann Arbor, MI 48109-5482, USA \\ Correspondence should be addressed to Leah L.Shever, sheverl@med.umich.edu \\ Received 29 September 2011; Revised 3 December 2011; Accepted 3 December 2011 \\ Academic Editor: John Daly
}

Copyright ( $) 2012$ L. L. Shever and M. G. Titler. This is an open access article distributed under the Creative Commons Attribution License, which permits unrestricted use, distribution, and reproduction in any medium, provided the original work is properly cited.

\begin{abstract}
The purpose of this study was to examine factors that contribute to adverse incidents by creating a model that included patient characteristics, clinical conditions, nursing unit context of care variables, medical treatments, pharmaceutical treatments, and nursing treatments. Data were abstracted from electronic, administrative, and clinical data repositories. The sample included older adults hospitalized during a four-year period at one, academic medical facility in the Midwestern United States who were at risk for falling. Relational databases were built and a multistep, statistical model building analytic process was used. Total registered nurse (RN) hours per patient day (HPPD) and HPPDs dropping below the nursing unit average were significant explanatory variables for experiencing an adverse incident. The number of medical and pharmaceutical treatments that a patient received during hospitalization as well as many specific nursing treatments (e.g., restraint use, neurological monitoring) were also contributors to experiencing an adverse incident.
\end{abstract}

\section{Background}

The Institute of Medicine (IOM) report To Err is Human [1] revealed the number and significance of adverse events and errors that occur during hospitalization. The report was a call to action to transform healthcare systems to ensure patient safety and higher quality care. In one step toward healthcare transformation, the Centers for Medicare and Medicaid (CMS) no longer reimburses institutions for the care, or treatment, associated with certain hospital-acquired conditions [2].

Understanding what factors contribute to adverse incidents during hospitalization is essential to developing effective counter measures. In order to improve factors that are modifiable within a hospital structure or with healthcare delivery, it is important to first have an understanding of what is broken. There are a number of potential contributing factors that need to be considered such as the patient's condition, the care the patient receives, and the environment in which they receive care $[3,4]$.
Battles and Lilford [3] provide a conceptual model for patient safety that includes antecedent conditions, which would include the patient's comorbid conditions, the primary reason the patient was admitted to the hospital, and characteristics the patient possessed before entering the hospital. Their model also includes the structure, or environment, in which the patient receives care such as the hospital, or nursing unit. Also acting within the structure are the processes of care (the interventions or treatments) delivered by the multidisciplinary team caring for the patient in the hospital. None of these components exist in isolation, which is why it is important to examine all of these factors and how they interact [3].

\section{Purpose}

The purpose of this study was to examine factors that contribute to adverse incidents that occur during hospitalization by creating a model that included patient characteristics, clinical conditions, nursing unit context of care variables, 


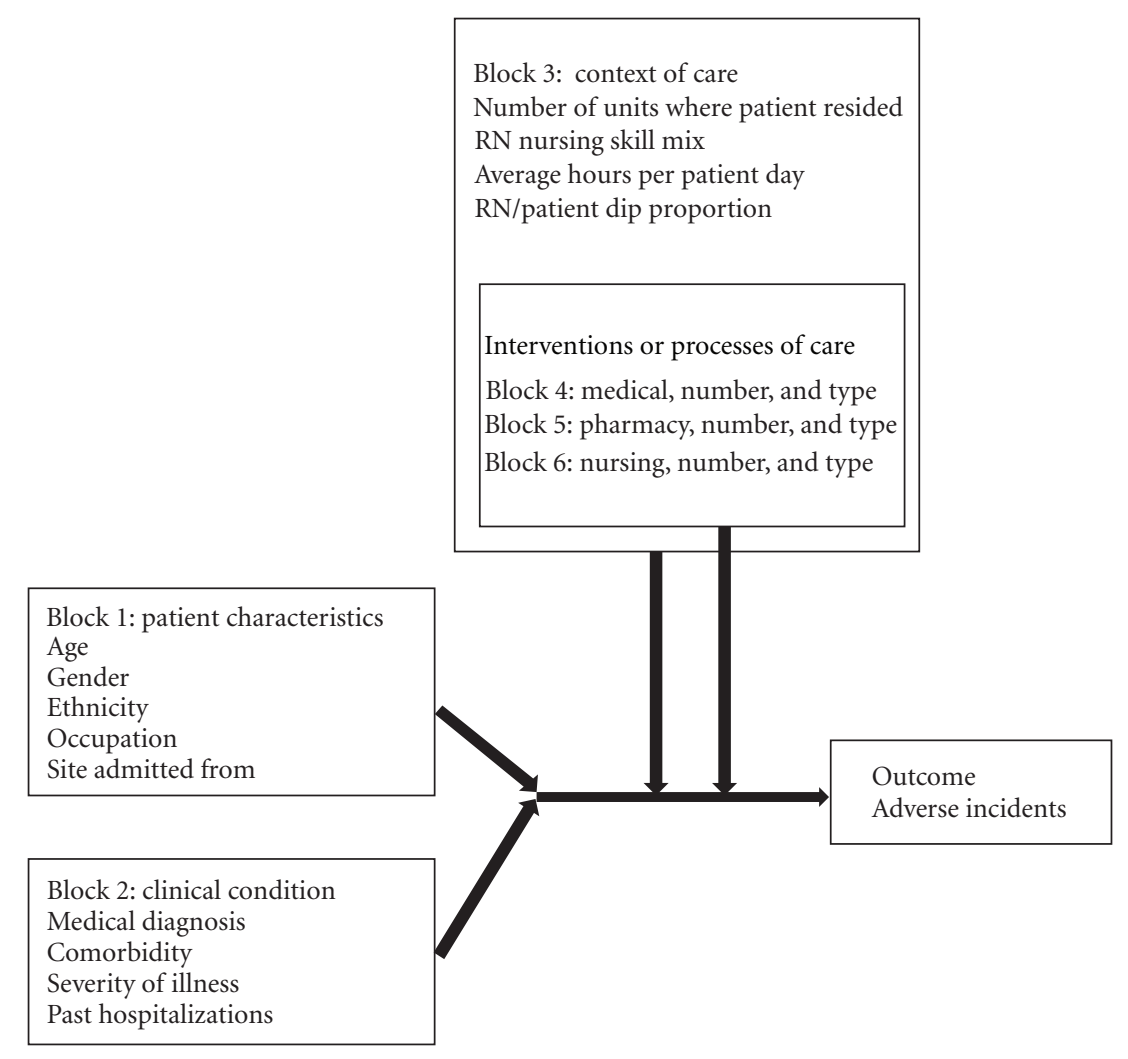

FIGURE 1: Model for predicting adverse incidents in the hospital.

medical treatments, pharmaceutical treatments, and nursing treatments. The research question addressed in this study is: what patient characteristics, clinical conditions, context of nursing care variables (e.g., nursing hours per patient day, RN skill mix, number of units resided on during hospitalization), and treatments (medical, pharmaceutical, and nursing treatments) explain the occurrence of adverse incidents for hospitalized, older adults at risk for falling? A model that has been used successfully to guide multidisciplinary effectiveness research in the hospital setting can be seen in Figure $1[5,6]$.

\section{Methods}

Data for this exploratory study came from a large, health service effectiveness grant [7] and was approved by the institution's Human Subjects review board. Data from a fouryear period (July 1, 1998 to June 31, 2002) were extracted for the primary study from one large Midwestern academic medical center. Data sources came from nine electronic data repositories, including the nursing information system that used the Nursing Interventions Classification (NIC) [8] to electronically document nursing care delivered. Detail of the nine electronic repositories and methods to assure validity and reliability are discussed elsewhere [5]. Extracted data were stored in a structured query language (SQL) server and relational databases were built using a unique subject number.
3.1. Sample. The inclusion criteria were hospitalizations to one Midwestern tertiary care hospital over a four-year period, patients 60 years of age or older upon admission, and at risk of falling. Patients were determined to be at risk of falling based on a fall risk assessment [6] that was completed upon admission or when the patient received the nursing intervention of Fall Prevention as recorded in the electronic documentation system. Patients at risk for falling were selected with the rationale that they would be at risk for experiencing one adverse incident (i.e., falling), and therefore interventions would be initiated to prevent the adverse incident. In addition, the hospitalizations were selected as the unit of analysis rather than individual patients and a variable was included to control for patients who had more than one hospitalization.

3.2. Study Variables. Conceptual and operational definitions for the independent variables included in the explanatory model are displayed in Table 1 and organized by the conceptual model seen in Figure 1 (patient characteristics, clinical conditions, context of care, and treatments). When appropriate, the source used to guide coding of variables is provided; for example, pharmaceutical treatments, or medications, were coded using the American Hospital Formulary Service (AHFS) codes [9].

The dependent variable for this analysis was the first occurrence of an adverse incident during an episode of hospitalization. Adverse incidents were defined as any undesired 


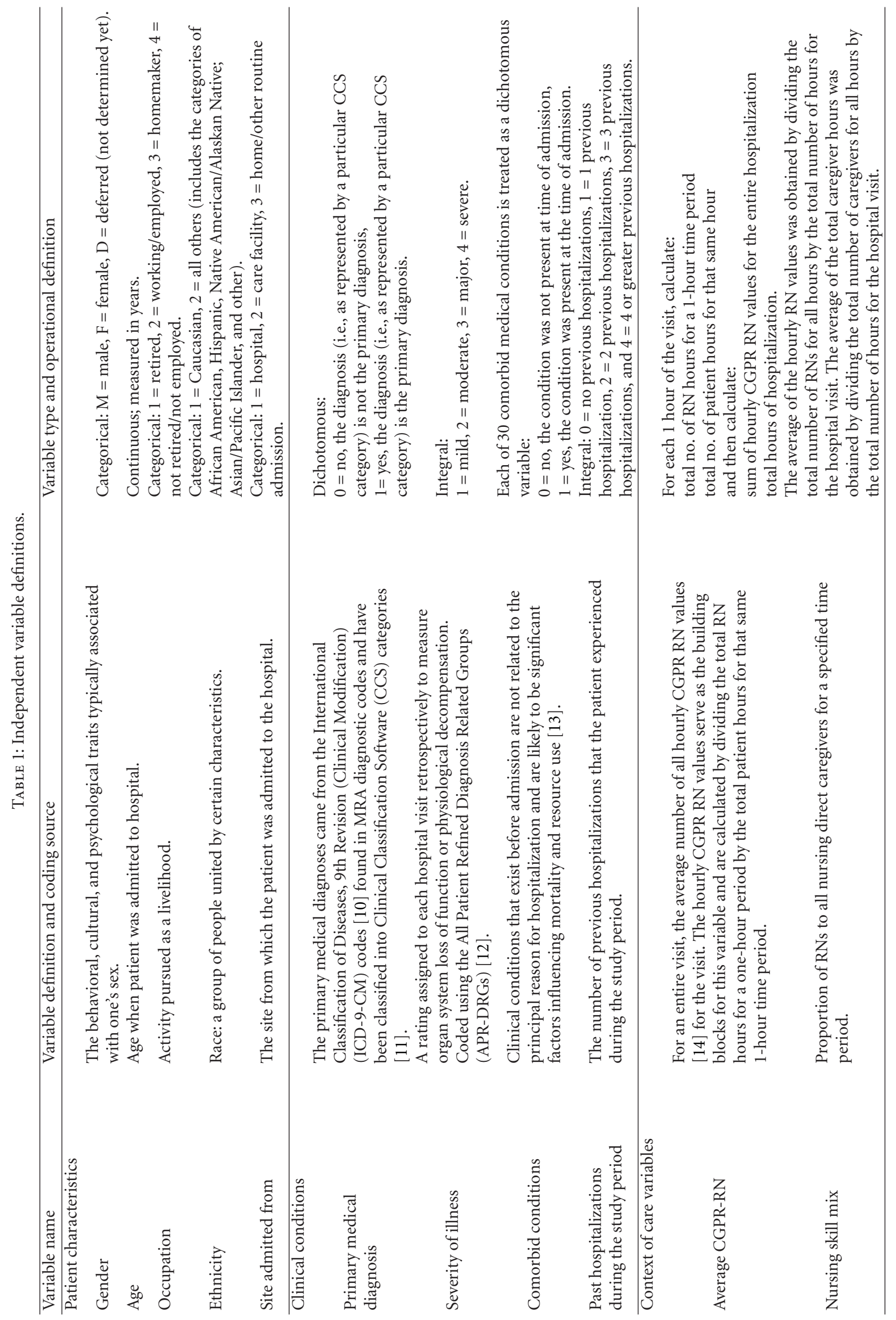




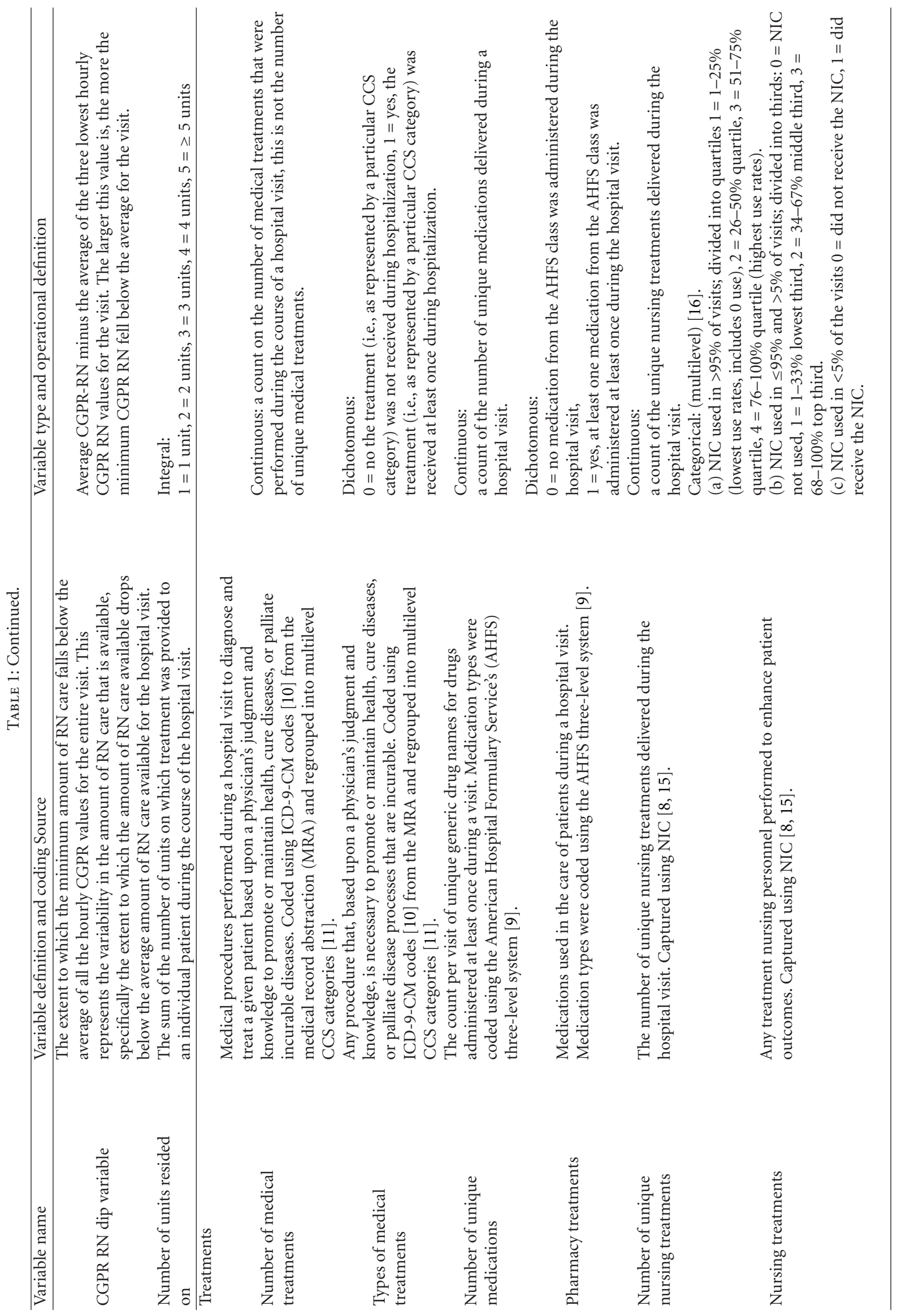


circumstance that lead to, or could have led to, personal harm. Adverse incidents were collected by the internal incident reporting system at the institution. Adverse incidents included falls, medication errors, procedure-related events (e.g., wrong patient, wrong procedure or test), equipmentrelated events (e.g., equipment malfunction, unplanned removal, improper set-up), and new conditions (e.g., skin breakdown).

\section{Analytic Procedures}

Due to the large number of study variables, a four-step model building process using logistic regression was used to answer the research question.

4.1. Step One. Each independent variable included in the analysis was tested independently using a bivariate analysis and a Score Statistic to determine the association with occurrence of an adverse incident. In this bivariate analysis, no other variables were statistically controlled for. Variables with $P$ values $\leq 0.15$ were retained for step two. A $P$ value $\leq 0.15$ was used as the criterion to guard against eliminating variables too soon in this exploratory analysis.

4.2. Step Two. The variables retained in step one ( $P$ values $\leq$ 0.15 ) were then analyzed within their respective conceptual variable blocks (i.e., patient characteristics, clinical conditions, context of care, medical treatments, pharmaceutical treatments, and nursing treatments) using logistic regression. A backward elimination process was used, indicating that the variable with the largest $P$ value was eliminated and the analysis was rerun on the remaining variables within the block. This procedure was repeated until all variables within the block had a $P$ value $\leq 0.15$. A $P$ value of $\leq 0.15$ during step two was chosen to guard against eliminating variables too soon because they might yet prove to have a statistically significant effect when combined with variables from other conceptual blocks.

4.3. Step Three. A model integrating all of the conceptual variable blocks was built in a progressive fashion using the variables that were retained in step two. The significant variables were added to the model by their respective blocks. Starting with the significant variables in block one (patient characteristics) and block 2 (clinical conditions), a model was built using the backward elimination process described in step two until the only variables remaining in the model were those with a $P$ value $\leq 0.15$. The significant variables from block three (context of care) were then added to what remained of blocks one (patient characteristics) and two (clinical conditions) in the model. Once again, a backward elimination process was performed until the only variables remaining in the model were those with values $\leq 0.15$. This process of adding blocks and using the backward elimination continued until the last block (nursing treatments) was added. At this point, when the significant variables from the final block were added and backward elimination was performed, the criterion for significance was decreased to a $P$ value $\leq 0.05$. This resulted in a final model containing only those variables with a $P$ value $\leq 0.05$. In step three, variables with a $P$ value $\leq 0.05$ in the logistic regression indicated that variables were significantly related to the dependent variable (occurrence of an adverse incident) after controlling for the other variables in the model.

4.4. Step Four. Covariates used for risk adjustment included age, severity of illness, and number of hospitalizations during the study period (see Table 2). Step four added these covariates used for risk adjustment (severity of illness, age, and more than one hospitalization during the study period) to the model to those that were significant in step three. Categorical variables with more than two categories were analyzed by comparing each level to a reference category. For example, severity of illness (four levels from minor to severe) was analyzed by comparing each of the three upper level categories to the lowest level of severity of illness (i.e., minor).

\section{Results}

There were 10,157 hospitalizations included in this analysis, comprised of 7,851 unique patients. The mean age was 73.7 years; most were retired (74.4\%), Caucasian (93.5\%), female $(52.6 \%)$, and admitted from home $(64.4 \%)$. This patient group, defined primarily by receiving the nursing treatment Fall Prevention, was medically diverse. The most common primary medical diagnoses were diseases of the circulatory system $(28.5 \%)$, neoplasms $(13.8 \%)$, and injury, including fractures, or poisoning $(11.5 \%)$.

There were 1,568 hospitalizations that experienced at least one adverse incident in this sample. The most commonly experienced adverse incident for this patient group included medication errors (37\%), falls (27\%), and equipment-related events (14\%).

Results of the model building process are illustrated in Table 2 by variable blocks. The bivariate correlations completed in step one are not included in Table 2 due to space constraints but are available from the authors upon request. The second column in Table 2 illustrates variables retained from step one that were analyzed within blocks with $P$ values $\leq 0.15$ (step two of model building) and thus retained for step three. The third column includes $P$ values from the third part of the modeling building process, prior to adding covariates used for risk adjustment to the final model (step four). The final model is illustrated in Table 3.

Five patient characteristics entered step one of the model building process but none were significant beyond step two. Age, although not significant in any of the three model building steps, was entered in the final model for risk adjustment [17]. Age was not significant in the final model (see Table 3).

Nine primary medical diagnoses were retained from step two, four were retained from step three, and three were retained $(P \leq 0.05)$ in the final model (see Tables 2 and 3). As the results in Table 3 indicate, other nervous system disorders, other primary cancer and senility and organic mental disorders were all significant $(P \leq 0.05)$ in the final model. Other nervous system disorders was the only 
TABLE 2: Results from the model building process for determining explanatory variables of experiencing an adverse incident.

\begin{tabular}{|c|c|c|}
\hline Variable & $\begin{array}{l}\text { Significant } P \text { values }(P \leq 0.15) \\
\text { for within block correlations }\end{array}$ & $\begin{array}{l}\text { Significant } P \text { values }(P \leq 0.05) \\
\text { for the final model }\end{array}$ \\
\hline \multicolumn{3}{|l|}{ Patient characteristics } \\
\hline Ethnicity & 0.0029 & \\
\hline Site admitted from & $<0.0001$ & \\
\hline \multicolumn{3}{|l|}{ Clinical conditions } \\
\hline \multicolumn{3}{|l|}{ Primary medical diagnoses ( $\%$ of sample) } \\
\hline Cancer, other primary $(1.7)$ & $<0.0001$ & 0.0010 \\
\hline Maintenance chemotherapy, radiotherapy (1.1) & 0.1408 & \\
\hline Fluid and electrolyte disorder (1.6) & 0.0172 & \\
\hline Senility \& organic mental disorders (3.0) & $<0.0001$ & 0.0140 \\
\hline Affective (2.1) & 0.0007 & \\
\hline Other nervous system disorders (1.1) & 0.0686 & 0.0176 \\
\hline Respiratory $(3.1)$ & 0.0687 & \\
\hline Chronic obstructive pulmonary (1.8) & 0.0332 & \\
\hline Symptoms, signs, and ill-defined conditions (1.8) & 0.1034 & \\
\hline Severity of illness & $<0.0001$ & \\
\hline Congestive heart failure (11.8) & 0.0155 & \\
\hline Other neurological disorders (3.6) & 0.1218 & \\
\hline Diabetes $(17.7)$ & 0.0347 & \\
\hline Peptic ulcer disease without bleeding (4.4) & 0.0985 & \\
\hline Rheumatoid arthritis/collagen vas (4.0) & 0.0918 & \\
\hline Psychoses $(5.7)$ & 0.0211 & \\
\hline Depression (6.6) & 0.0237 & \\
\hline \multicolumn{3}{|l|}{ Severity of illness } \\
\hline Severity of illness & $<0.0001$ & \\
\hline \multicolumn{3}{|l|}{ Elixhauser comorbid conditions (\% of sample) } \\
\hline Congestive heart failure (11.8) & 0.0155 & \\
\hline Other neurological disorders (3.6) & 0.1218 & \\
\hline Diabetes $(17.7)$ & 0.0347 & \\
\hline Peptic ulcer disease without bleeding (4.4) & 0.0985 & \\
\hline Rheumatoid arthritis/collagen vas (4.0) & 0.0918 & \\
\hline Psychoses (5.7) & 0.0211 & \\
\hline Depression $(6.6)$ & 0.0237 & \\
\hline \multicolumn{3}{|l|}{ Past hospitalizations } \\
\hline Past hospitalizations & 0.0199 & \\
\hline \multicolumn{3}{|l|}{ Context of care variables } \\
\hline Number of units resided on & $<0.0001$ & \\
\hline CGPR dip proportion & $<0.0001$ & 0.0092 \\
\hline Skill mix & 0.0003 & \\
\hline Average caregiver patient ratio & $<0.0001$ & $<0.0001$ \\
\hline \multicolumn{3}{|l|}{ Treatments } \\
\hline \multicolumn{3}{|l|}{ Medical treatments } \\
\hline Total number of procedures & $<0.0001$ & 0.0059 \\
\hline \multicolumn{3}{|l|}{ Types of medical treatments ( $\%$ of sample) } \\
\hline Incision and excision of CNS (2.0) & 0.0059 & \\
\hline Incision of pleura, thoracentesis, chest drainage (3.8) & 0.0637 & \\
\hline Coronary artery bypass graft (CABG) (3.1) & $<0.0001$ & \\
\hline
\end{tabular}


Table 2: Continued.

\begin{tabular}{|c|c|c|}
\hline Variable & $\begin{array}{l}\text { Significant } P \text { values }(P \leq 0.15) \\
\text { for within block correlations }\end{array}$ & $\begin{array}{l}\text { Significant } P \text { values }(P \leq 0.05) \\
\text { for the final model }\end{array}$ \\
\hline Diagnostic cardiac catheterization, coronary arteriography (7.9) & 0.0007 & \\
\hline Other therapeutic procedures, hemic and lymphatic system (2.8) & 0.1205 & \\
\hline Upper gastrointestinal endoscopy, biopsy (6.6) & 0.0062 & \\
\hline Gastrostomy, temporary and permanent (1.5) & 0.1035 & \\
\hline Oophorectomy, unilateral \& bilateral (1.3) & 0.0062 & \\
\hline Partial excision bone (1.5) & 0.0769 & \\
\hline Treatment of fracture or dislocation (2.3) & 0.0513 & \\
\hline Arthroplasty (3.0) & 0.0014 & \\
\hline Amputation of lower extremity (1.1) & 0.1257 & \\
\hline Spinal fusion $(1.0)$ & 0.0089 & \\
\hline Debridement of wound, infection or burn (1.5) & 0.0395 & \\
\hline Arterio or venogram (not heart or head) (2.2) & 0.0091 & \\
\hline Diagnostic ultrasound (33.5) & 0.0048 & \\
\hline Radioisotope scan (6.6) & 0.0667 & \\
\hline Physical therapy (4.7) & $<0.0001$ & 0.0015 \\
\hline Psychological and psychiatric evaluation and therapy (1.8) & $<0.0001$ & \\
\hline Enteral and parenteral nutrition (9.5) & 0.0063 & \\
\hline \multicolumn{3}{|l|}{ Pharmaceutical treatments } \\
\hline Number of unique medications & $<0.0001$ & $<0.0001$ \\
\hline \multicolumn{3}{|l|}{ Types of pharmaceutical treatments (\% of sample) } \\
\hline Sympathomimetic (adrenergic) agents (17.3) & 0.0241 & \\
\hline Anticholinergic agents (13.5) & 0.0054 & \\
\hline Skeletal muscle relaxants (5.4) & 0.0140 & \\
\hline Cardiac drugs (64.8) & 0.0445 & \\
\hline Hypotensive agents (37.7) & 0.0882 & \\
\hline Psychotherapeutic agents (35.0) & $<0.0001$ & \\
\hline Succinimides $(27.8)$ & $<0.0001$ & 0.0015 \\
\hline Miscellaneous central nervous system agents (3.9) & 0.0923 & \\
\hline Opiate antagonists (1.4) & 0.0669 & \\
\hline Anorexigenic agents and respiratory \& cerebral stimulants (1.4) & 0.0146 & \\
\hline Caloric agents $(51.8)$ & 0.0244 & 0.0128 \\
\hline Irrigating solutions (7.3) & 0.0414 & \\
\hline Ammonia detoxicants (2.7) & 0.0785 & 0.0274 \\
\hline EENT anti-infectives (42.2) & 0.0002 & 0.0148 \\
\hline EENT carbonic anhydrase inhibitors (2.2) & 0.0404 & \\
\hline Miscellaneous GI drugs (59.8) & 0.1098 & \\
\hline Parathyroid (1.4) & 0.0228 & \\
\hline Anti-infectives (21.5) & 0.0346 & \\
\hline Anti-inflammatory agents (6.8) & 0.0438 & \\
\hline Multivitamin preparations (18.7) & 0.0425 & \\
\hline Vitamin B complex (7.4) & 0.1130 & \\
\hline Unclassified therapeutic agents $(34.0)$ & 0.0619 & \\
\hline Tetracyclines (1.3) & 0.1135 & \\
\hline Opiate agonists (64.0) & 0.0034 & \\
\hline Barbiturates (2.8) & 0.0014 & \\
\hline Benzodiazepines (56.2) & 0.0024 & \\
\hline
\end{tabular}


Table 2: Continued.

\begin{tabular}{|c|c|c|}
\hline Variable & $\begin{array}{l}\text { Significant } P \text { values }(P \leq 0.15) \\
\text { for within block correlations }\end{array}$ & $\begin{array}{l}\text { Significant } P \text { values }(P \leq 0.05) \\
\text { for the final model }\end{array}$ \\
\hline Misc. anxiolytics, sedatives, \& hypnotics (17.8) & 0.0022 & \\
\hline \multicolumn{3}{|l|}{ Nursing treatments } \\
\hline \multicolumn{3}{|l|}{ Nursing treatment types ( $\%$ of sample) } \\
\hline Fluid management (99.5) & 0.0098 & \\
\hline Bathing (93.5) & 0.0600 & \\
\hline Pressure ulcer care (91.5) & $<0.0001$ & 0.0005 \\
\hline Bowel management (88.2) & 0.1049 & \\
\hline Teaching $(81.5)$ & 0.0003 & \\
\hline Discharge planning (76.0) & 0.0042 & \\
\hline Routine care: adult (56.2) & 0.0626 & \\
\hline Health screening (48.8) & $<0.0001$ & $<0.0001$ \\
\hline Sleep enhancement (47.7) & 0.0572 & \\
\hline Oxygen therapy (42.4) & 0.0008 & \\
\hline Post-op care $(27.8)$ & $<0.0001$ & \\
\hline Wound care (21.4) & 0.0137 & \\
\hline Neurologic monitoring (20.2) & 0.0002 & 0.0003 \\
\hline Analgesic administration (17.2) & 0.0723 & \\
\hline Fluid/electrolyte monitoring (15.1) & 0.0365 & \\
\hline Medication management (12.2) & 0.0678 & \\
\hline Nutrition management (11.3) & 0.0022 & \\
\hline Embolus precautions (9.4) & 0.0687 & \\
\hline Infection protection (8.9) & 0.0182 & \\
\hline Enteral tube feeding (9.4) & 0.0042 & \\
\hline Blood products administration (8.6) & 0.0004 & 0.0192 \\
\hline Restraint (8.5) & $<0.0001$ & $<0.0001$ \\
\hline Postprocedure care (5.6) & 0.0219 & \\
\hline Specimen management $(5.3)$ & 0.0079 & 0.0098 \\
\hline Active listening (4.8) & 0.0161 & 0.0003 \\
\hline Surgical preparation $(4.1)$ & 0.1281 & 0.0441 \\
\hline Total parenteral nutrition (TPN) administration: adult (3.4) & 0.0033 & \\
\hline Aspiration precautions (3.2) & 0.0233 & \\
\hline Anger control assistance (2.8) & 0.0177 & \\
\hline Mood management (2.5) & 0.0091 & 0.0004 \\
\hline Self-care assistance (2.2) & 0.1323 & \\
\hline Procedure preparation (2.1) & 0.1079 & \\
\hline Dementia management (1.6) & 0.0816 & \\
\hline Electroconvulsive therapy (1.6) & 0.0290 & \\
\hline Cast care: maintenance (1.1) & 0.0035 & 0.0037 \\
\hline Splinting (1.1) & 0.0086 & \\
\hline Music therapy (1.1) & 0.0036 & 0.0019 \\
\hline Medical immobilization (0.9) & 0.0356 & \\
\hline
\end{tabular}

primary medical diagnosis of the three inversely associated with experiencing an adverse incident (O.R. $=0.43$ ), indicating that hospitalizations with this medical diagnosis were less likely to suffer an adverse incident compared to hospitalizations that did not have this condition. Other primary cancer and senility and organic mental disorders were both positively associated with experiencing an adverse incident with odds ratios of 1.94 and 1.57, respectively.

Severity of illness, although not significant in step three, was entered into the final model for risk adjustment [17]. Severe and major severity of illness categories were significantly $(P \leq 0.05)$ and positively associated with 


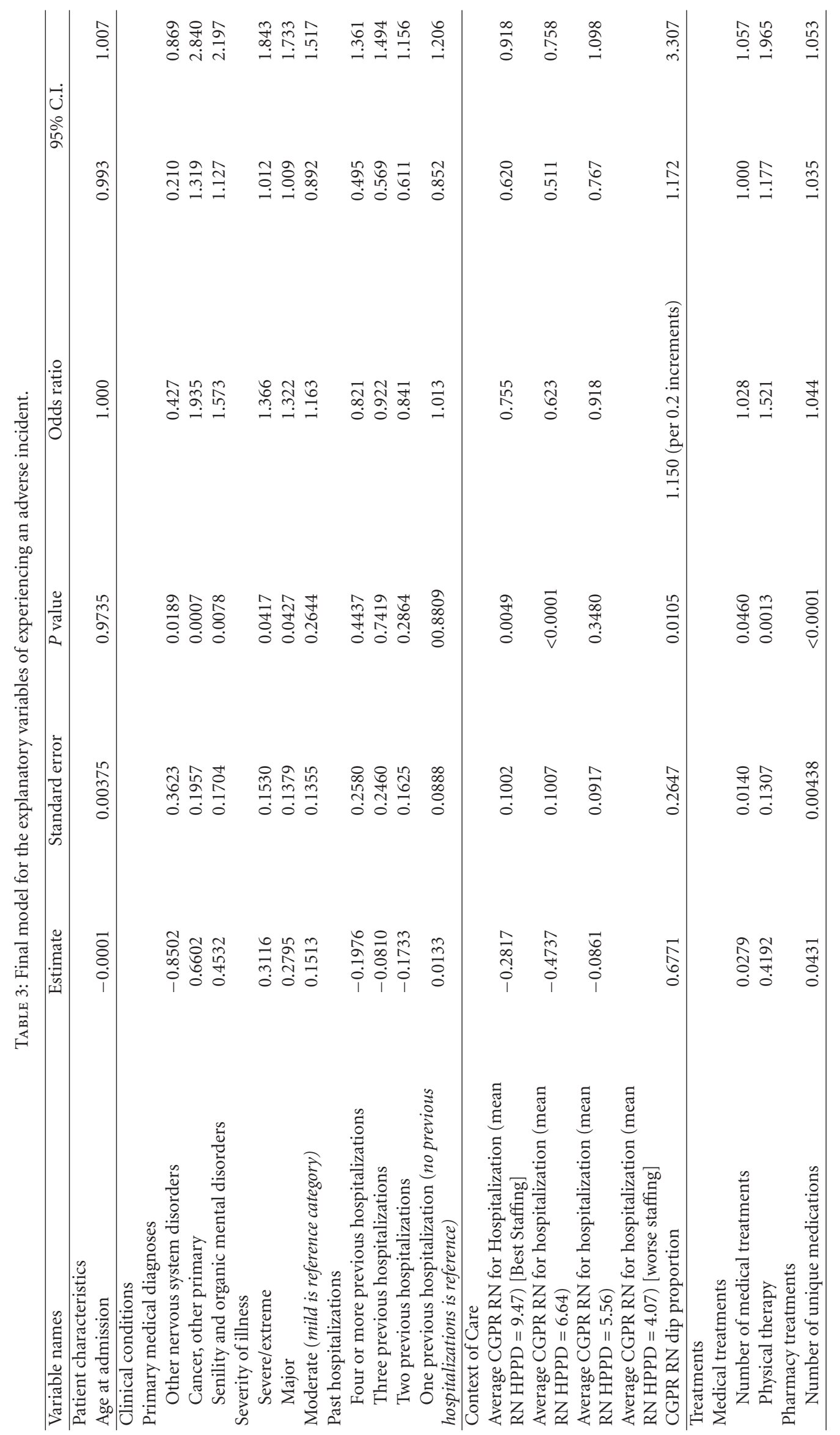




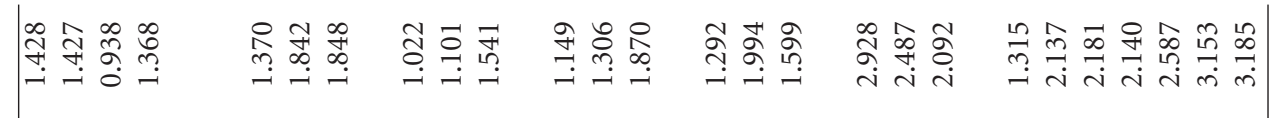

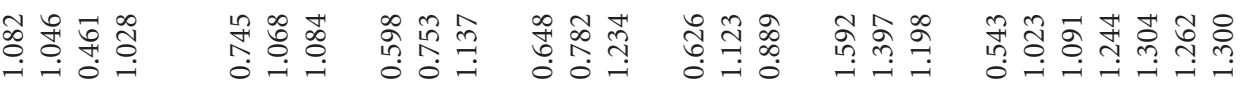

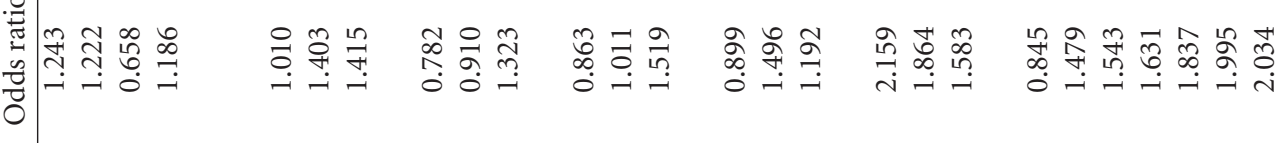

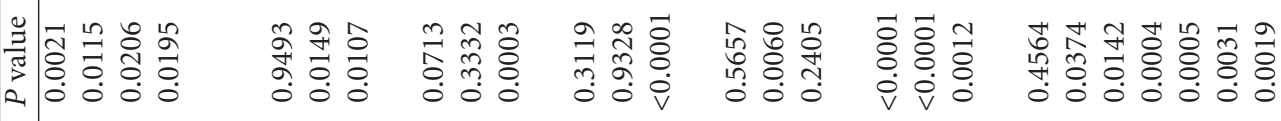

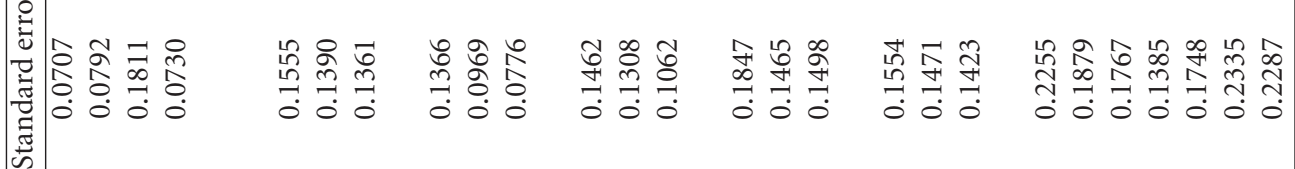

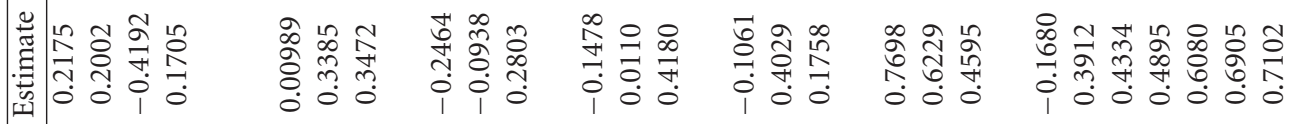

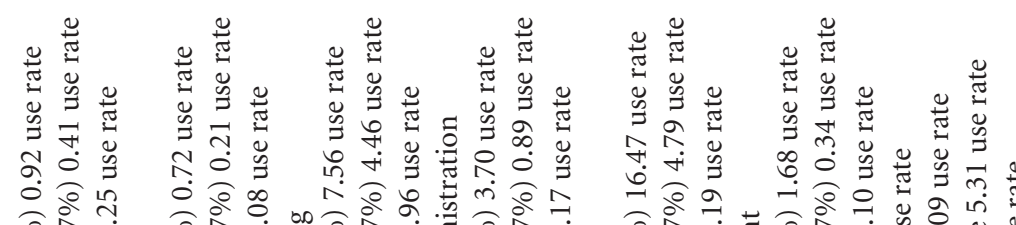

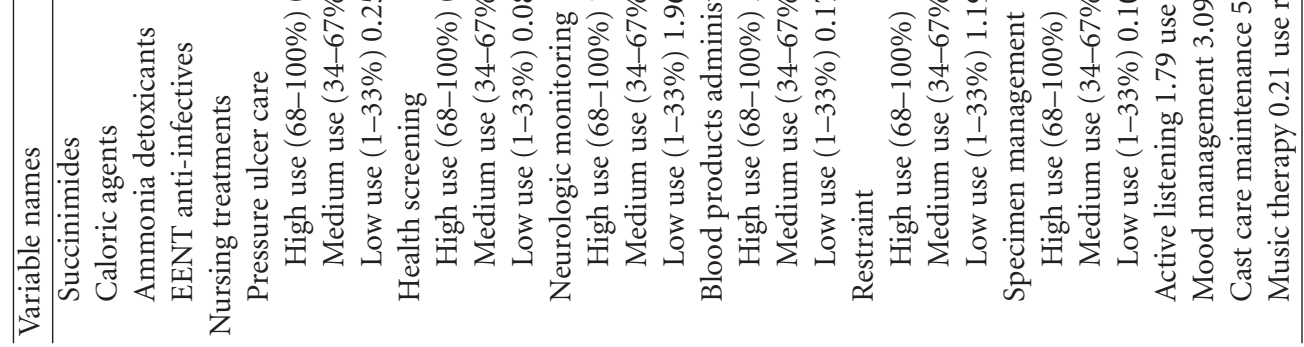


experiencing an adverse incident compared to the lowest severity of illness category (i.e., mild) (see Table 3).

Seven comorbid conditions were retained from step two for inclusion in step three but none were significant and thus were not retained for inclusion in the final model. Past hospitalizations during the study period were significant in step two but not in step three (see Table 2). However, this variable was entered into the final model to adjust for patients that had experienced more than one hospitalization during the study period. In the final model (Table 3) past hospitalizations were not significant.

Four context of care variables, the number of units the patient resided on during hospitalization, the dip proportion (falling below the unit's average staffing), skill mix, and the average Caregiver Patient Ratio (CGPR) [14], were significant in step two (see Table 2) but only two variables, the dip proportion and average CGPR, were significant in step three and retained for the final model (see Table 2). Both were significant in the final model (step four) as illustrated in Table 3. The average CGPR ( $\mathrm{RN}$ hours per patient day (HPPDs)) was categorized as quartiles to enable comparison and interpretation for this nonlinear variable. The two highest average CGPR quartiles (9.5 RN HPPDs and 6.6 RN HPPDs) were significantly $(P \leq 0.05)$ and inversely associated with experiencing an adverse incident, indicating that when compared to the lowest quartile of staffing (4.1 RN HPPDs), the odds of experiencing an adverse incident decreased in the highest two quartiles of nursing hours per patient day. The odds of experiencing an adverse incident for hospitalizations with the highest average CGPR quartile (9.5 RN HPPDs) were 0.76 of the odds for hospitalizations that experienced the lowest average CGPR quartile (4.1 RN HPPDs). The odds of experiencing an adverse incident for hospitalizations with the second highest average CGPR (6.6 RN HPPDs) were 0.62 of the odds for hospitalizations in the lowest CGPR average quartile.

The CGPR dip proportion was significantly $(P=0.011)$ and positively associated with experiencing an adverse incident. The results shown in Table 3 are in terms of 0.2 increments of change and indicate that for each $20 \%$ fall in staffing below the average, the odds of experiencing an adverse incident increase by 15\% (O.R. $=1.15)$.

The number of medical treatments received during hospitalization and 20 types of medical treatment were significant in step two (see Table 2) and were therefore included in step three. In step three of the analysis, the number of medical treatments received during hospitalization and one medical treatment type, physical therapy, were significant $(P \leq 0.05)$ and retained for the final model. Both were positively associated with experiencing an adverse incident (see Tables 2 and 3). The results indicate that for each additional medical treatment received during hospitalization, the odds of experiencing an adverse incident increased by approximately $3 \%(\mathrm{O} . \mathrm{R} .=1.03)$. Hospitalizations that received the medical treatment physical therapy were 52\% $(\mathrm{O} . \mathrm{R} .=1.52)$ more likely to experience an adverse incident than hospitalizations that did not receive this medical treatment.
The number of unique medications received during hospitalization and 27 specific pharmaceutical treatments (i.e., medications types) were significant in step two of the analysis $(P \leq 0.15)$ and thus retained for step three. The number of unique medication types and four types of medications were significant in step three (see Table 2) and all were significant in the final model (see Table 3). The number of unique medications was positively associated $(P<0.001)$ with experiencing an adverse incident (O.R. $=1.04)$. Receipt of succinimides, caloric agents, and EENT anti-infectives during hospitalization increased the odds of an adverse incident. Ammonia detoxicants were inversely associated $(P=0.021)$ with experiencing an adverse incident $(\mathrm{O} . \mathrm{R} .=0.46)$.

In step two of the analysis, the number of unique nursing treatments received during hospitalization was not significant but 38 types of nursing treatments were significant $(P \leq 0.15)$ and entered into step three (see Table 2). Eleven were significant at step three and ten were significant in the final model (see Tables 2 and 3). Surgical preparation was not significant in the final model. The nursing treatment pressure ulcer care, received by $91.5 \%$ of the sample, was divided into thirds based on the average number of times per day it was delivered (see Table 1). The results for the three categories of use are interpreted in comparison to hospitalizations that did not receive the nursing treatment. The middle and low use categories of pressure ulcer care were significantly $(P \leq 0.05)$ and positively associated with experiencing an adverse incident, indicating that hospitalizations that received pressure ulcer care a little less than once every other day (use rate $=0.41$ ) or once every four days (use rate $=0.25$ ) were more likely to experience an adverse incident than hospitalizations that did not receive pressure ulcer care. A similar pattern emerged with the nursing treatment of specimen management. The medium (use rate $=0.34$ ) and low (use rate $=0.10$ ) categories were significantly $(P \leq 0.05)$ and positively associated with experiencing an adverse incident (see Table 3 ).

Both health screening and neurologic monitoring had low use categories that were significantly $(P \leq 0.05)$ and positively correlated with experiencing an adverse incident. The results indicate that hospitalizations that received the low use of these two nursing treatments were more likely to experience an adverse incident than hospitalizations that did not receive the associated nursing treatment (see Table 3 ).

The medium use category of blood products administration (use rate $=0.89)$ was significantly $(P \leq 0.05)$ and positively $(\mathrm{O} . \mathrm{R} .=1.49)$ associated with experiencing an adverse incident. Hospitalizations that received Blood Products Administration a little less than once a day were almost 50\% more likely to experience an adverse incident than hospitalizations that did not receive blood products administration.

All three categories of use for the nursing treatment Restraint were significantly $(P<0.01)$ and positively associated with experiencing an adverse incident (see Table 3 ). The high use category had an average delivery of 16.47 times a day and hospitalizations that received high use of restraint had more than double the odds $(\mathrm{O} . \mathrm{R} .=2.16)$ of experiencing an adverse incident compared to hospitalizations that did 
not receive this nursing treatment. Hospitalizations that received restraint approximately four and a half times a day (medium use category) had almost double the odds $(\mathrm{O} . \mathrm{R} .=1.86)$ of experiencing an adverse incident compared to hospitalizations that did not receive restraint. The lowest category of use was delivered an average a little more than once a day and increased the likelihood of experiencing an adverse incident by $58 \%(\mathrm{O} . \mathrm{R} .=1.58)$ compared to no use.

The remaining significant nursing treatments were delivered to less than $5 \%$ of the sample and were therefore operationalized as dichotomous variables so that hospitalizations that received the nursing treatment at least once are compared to hospitalizations that did not receive the treatment (see Table 1 for definition). Active listening received at least once by $4.8 \%$ of the sample was significantly $(P<0.001)$ and positively $($ O.R. $=1.63)$ associated with experiencing an adverse incident.

Mood management was received by only $2.5 \%$ of the sample but was delivered an average of 3.1 times per day when it was delivered. Hospitalizations that received mood management almost doubled their odds (O.R. = 1.84) of experiencing an adverse incident compared to hospitalizations that did not receive mood management.

Cast care maintenance was another nursing treatment that was delivered frequently (more than five times a day on average) when hospitalizations required it. Receiving this nursing treatment doubled the odds (O.R. $=2.00)$ of experiencing an adverse incident compared to hospitalizations that did not receive this nursing treatment.

Slightly more than one percent of the sample received the nursing treatment music therapy. The average use rate for hospitalizations that received this treatment was slightly more than once every ten days (use rate $=0.21$ ). The odds of experiencing an adverse incident were double (O.R. = 2.03) for hospitalizations that received this nursing treatment compared to hospitalizations that did not receive music therapy (see Table 3).

\section{Discussion}

None of the patient characteristics were significant, indicating that patient characteristics were not explanatory variables of adverse incidents, given the other variables that entered the model. Also nonsignificant were two clinical conditions: number of past hospitalizations during the study period and comorbid medical conditions. This indicates that after controlling for other variables in the model, patient characteristics of this sample of older adults were not significant for experiencing an adverse incident during hospitalization.

Three primary medical diagnoses were significant explanatory variables associated with experiencing an adverse incident. Other nervous system disorders were inversely associated with experiencing an adverse incident. This inverse relationship may be explained by considering the type of nursing unit these patients are typically admitted to. A primary medical diagnosis of nervous system disorder, which is composed of peripheral and central nervous system disorders along with more generic symptoms of a nervous system disorder [11], would likely warrant admission to a neurology unit in this academic medical setting where the nursing personnel are skilled in the care of these patients and may recognize the need for increased surveillance. This heightened surveillance for these specialized patients may decrease adverse incidents.

Other primary cancer was positively associated with experiencing an adverse incident. Patients hospitalized with the primary medical diagnosis of other primary cancer are on high-risk medications, some that call for double-checks, and that may increase the number of medication errors that are discovered. The third primary medical diagnosis, senility and organic mental disorders, appears similar in nature to other nervous system disorders but is positively associated with experiencing an adverse incident, unlike other nervous system disorders. This may be because patients who have senility and organic mental disorders are less capable of using safety equipment in their environment like call lights and hand rails and are more likely to be dispersed among a variety of general medical or surgical units. The environment and specialized nursing expertise may not be readily available to meet the unique care demands of individuals with this primary medical condition. In the final model, the top two severities of illness categories (i.e., severe and major) were significantly and positively associated with experiencing an adverse incident. This is not surprising, as patients who are sicker often have complex care issues which may place them at greater risk to experience an adverse incident.

Related to the structure of care (context of care), the two highest categories of the average CGPR (RN HPPDs) were significantly and inversely associated with experiencing an adverse incident compared to the lowest quartile, indicating that when there are more nursing hours per patient day, there is a decreased likelihood of preventing an adverse incident. This is consistent with findings from previous research [1824].

The CGPR RN dip proportion was positively associated with adverse incidents. The more the RN staffing fell below the nursing unit average, the more likely an adverse incident was to occur during that hospitalization. This finding indicates that not only is the number of nurses, or HPPDs, an important predictor of adverse incidents but so is staffing below the average on a nursing unit. This may indicate that units develop effective processes dependent upon their average staffing and when the staffing is altered, the processes are impacted. Staffing below the unit average places the patient at greater risk for having an adverse incident

Processes of care included medical, pharmaceutical, and nursing treatments. Both the number of medical treatments and the number of unique medications received during hospitalization were positively associated with experiencing an adverse incident. As the number of procedures and medications increased so did the odds of having an adverse incident (e.g., medication error, wrong site surgery, trauma, etc.).

There was one medical treatment, physical therapy, and two medication types, succinimides and ammonia detoxicants, that were significantly associated with experiencing an adverse incident, which may be related to falls. The positive association between physical therapy and adverse 
incidents may be a reflection of patients with decreased functional status who are at greater risk for falling. Similarly, succinimides are anticonvulsives and are in the same AHFS class as barbiturates and benzodiazepines [9], which are positively associated with falls [25]. Ammonia detoxicants was the only pharmaceutical treatment in the final model inversely associated with experiencing an adverse incident (see Table 3). Patients who require ammonia detoxicants often have conditions associated with liver dysfunction, which makes it more difficult for them to excrete ammonia that builds up in their body. Patients that have high ammonia levels are often confused, disoriented, difficult to direct, and are at great risk for falling for these reasons.

The nursing treatments associated with adverse incidents were diverse. There was one nursing treatment, pressure ulcer care, that is used to treat an adverse incident (i.e., pressure ulcer). There were also a number of nursing treatments positively associated with adverse incidents where providing the treatment showed that the patient likely had greater exposure to an adverse incident than patients who did not receive the treatment. One example is the nursing treatment specimen management where a patient is more likely to have a mislabeled lab as an adverse incident than a patient who did not receive this treatment. The same could be true for blood product administration and cast care maintenance.

Similarly, all three categories of Restraint were significantly and positively associated with experiencing an adverse incident. Only $8.5 \%$ of the hospitalizations in this sample received restraint at least once but the use rates were relatively high, especially the high use category with an average delivery of 16.47 times per day. These findings also show that use of restraints does not prevent adverse incidents (e.g., falls) and in fact may contribute to them as has been demonstrated in other research $[26,27]$.

Active listening, mood management, and music therapy may be used as complementary therapies for patients who are distressed, confused, or combative when other treatments have not worked. Hospitalizations that require these nursing treatments may be at greater risk for falling because the patient is unable to follow commands, is impulsive or unable to communicate effectively.

\section{Limitations}

This study was conducted at one academic medical center and therefore further multisite research is needed. Although the effectiveness research model used in this study includes many important, patient and multidisciplinary components, there were important aspects of care that impact patient safety such as the individual characteristics of the clinicians involved in care (e.g., experience, education) and how they interact with one another (e.g., teamwork, communication) that were not included in this study [28].

\section{Conclusion}

This study examined a number of patient conditions, structural variables, and process of care variables to better understand what factors contribute to adverse incidents during hospitalization. This is one of the first studies to show that delivered nursing treatments help explain adverse incidents in hospitalized, older adults. This study also used a multidisciplinary model that considered medical and pharmaceutical components of treatment, which are critical when providing care of the older adult in acute care. With this more robust multidisciplinary model, $\mathrm{RN}$ staffing was still an important explanatory variable for adverse incidents, which is congruent with findings from other research [29, 30].

\section{Acknowledgment}

This research was supported by a Grant from NIH (PI: Titler. NINR 1 R01 NR05331).

\section{References}

[1] Institute of Medicine, To Err Is Human: Building a Safer Health System, National Academy of Sciences, Washington, DC, USA, 2000.

[2] U.S. Department of Health and Human Services Centers for Medicare and Medicaid Services, Hospital Acquired Conditions. http://www.cms.gov/HospitalAcqCond/06_HospitalAcquired_Conditions.asp.

[3] J. B. Battles and R. J. Lilford, "Organizing patient safety research to identify risks and hazards," Quality and Safety in Health Care, vol. 12, supplement 2, pp. ii2-ii7, 2003.

[4] M. Duckers, M. Faber, J. Cruijsberg, R. Grol, L. Schoonhoven, and M. Wensing, "Safety and risk management interventions in hospitals: a systematic review of the literature," Medical Care Research and Review, vol. 66, suppement 6, pp. 90S-119S, 2009.

[5] M. Titler, J. Dochterman, X. J. Xie et al., "Nursing interventions and other factors associated with discharge disposition in older patients after hip fractures," Nursing Research, vol. 55, no. 4, pp. 231-242, 2006.

[6] M. Titler, J. Dochterman, D. M. Picone et al., "Cost of hospital care for elderly at risk of falling," Nursing Economics, vol. 23, no. 6, pp. 290-306, 2005.

[7] M. Titler, "Nursing interventions and outcomes effectiveness in 3 older populations," Tech. Rep. NR05331-02, National Institute of Nursing Research (NINR), Rockville, Md, USA, 2000.

[8] J. M. Dochterman and G. M. Bulechek, Nursing Interventions Classification (NIC), Mosby, St. Louis, Mo, USA, 4th edition, 2004.

[9] G. K. McEvoy, American Hospital Forumlary Service (AHFS) Drug Information 2000, American Society of Health System Pharmacists, Bethesda, Md, USA, 2000.

[10] Public Health Service and Health Care Financing Administration, ICD-9-CM: International Classification of Diseases, 9th Revision, Clinical Modification, Public Health Service, Washington, DC, USA, 1994.

[11] Agency for Healthcare Research and Quality (AHRQ), Healthcare Cost and Utilization Project (HCUP), Clinical Classifications Software (CCS) for ICD-9-CM, Rockville, Md, USA, 2002.

[12] 3M Health Information Systems, All Patient Refined Diagnosis Related Groups (APR-DRGs), 3M Health Information Systems, Wallingford, Conn, USA, 1993. 
[13] A. Elixhauser, C. Steiner, D. R. Harris, and R. M. Coffey, "Comorbidity measures for use with administrative data," Medical Care, vol. 36, no. 1, pp. 8-27, 1998.

[14] G. Budreau, R. Balakrishnan, M. Titler, and M. J. Hafner, "Caregiver-patient ratio: capturing census and staffing variability," Nursing Economics, vol. 17, no. 6, pp. 317-324, 1999.

[15] M. Titler, J. Dochterman, and D. Reed, Guideline for Conducting Effectiveness Research in Nursing and Other Health Services, The University of Iowa, College of Nursing, Center for Nursing Classification \& Clinical Effectiveness, Iowa City, Iowa, USA, 2004.

[16] D. Reed, M. G. Titler, J. M. Dochterman, L. L. Shever, M. Kanak, and D. M. Picone, "Measuring the dose of nursing intervention," International Journal of Nursing Terminologies and Classifications, vol. 18, no. 4, pp. 121-130, 2007.

[17] L. Iezzoni, Risk Adjustment for Measuring Health Care Outcomes, Health Administration Press, Chicago, Ill, USA, 3rd edition, 2003.

[18] S. H. Cho, S. Ketefian, V. H. Barkauskas, and D. G. Smith, "The effects of nurse staffing on adverse events, morbidity, mortality, and medical costs," Nursing Research, vol. 52, no. 2, pp. 71-79, 2003.

[19] N. Dunton, B. Gajewski, R. L. Taunton, and J. Moore, "Nurse staffing and patient falls on acute care hospital units," Nursing Outlook, vol. 52, no. 1, pp. 53-59, 2004.

[20] L. M. Hall, D. Doran, and G. H. Pink, "Nurse staffing models, nursing hours, and patient safety outcomes," Journal of Nursing Administration, vol. 34, no. 1, pp. 41-45, 2004.

[21] P. Potter, N. Barr, M. McSweeney, and J. Sledge, "Identifying nurse staffing and patient outcome relationships: a guide for change in care delivery," Nursing Economics, vol. 21, no. 4, pp. 158-166, 2003.

[22] M. D. Sovie and A. F. Jawad, "Hospital restructuring and its impact on outcomes: nursing staff regulations are premature," Journal of Nursing Administration, vol. 31, no. 12, pp. 588-600, 2001.

[23] L. Unruh, "Licensed nurse staffing and adverse events in hospitals," Medical Care, vol. 41, no. 1, pp. 142-152, 2003.

[24] G. R. Whitman, Y. Kim, L. J. Davidson, G. A. Wolf, and S. L. Wang, "The impact of staffing on patient outcomes across specialty units," Journal of Nursing Administration, vol. 32, no. 12, pp. 633-639, 2002.

[25] J. C. Woolcott, K. J. Richardson, M. O. Wiens et al., "Metaanalysis of the impact of 9 medication classes on falls in elderly persons," Archives of Internal Medicine, vol. 169, no. 21, pp. 1952-1960, 2009.

[26] J. V. Agostini, D. I. Baker, and S. T. Bogardus Jr, "Prevention of falls in hospitalized and institutionalized older people," in Making Health Care Safer: A Critical Analysis of Patient Safety Practices. Evidence Report/Technology Assessment no. 43, K. G. Shojania, B. W. Duncan, and K. M. McDonald, Eds., Agency for Healthcare Research and Quality (AHRQ), Rockville, Md, USA, 2001.

[27] D. Evans, J. Wood, and L. Lambert, "A review of physical restraint minimization in the acute and residential care settings," Journal of Advanced Nursing, vol. 40, no. 6, pp. 616625,2002

[28] T. Hoff, L. Jameson, E. Hannan, and E. Flink, "A review of the literature examining linkages between organizational factors, medical errors, and patient safety," Medical Care Research and Review, vol. 61, no. 1, pp. 3-37, 2004.

[29] R. L. Kane, T. Shamliyan, C. Mueller, S. Duval, and T. J. Wilt, "Nurse staffing and quality of patient care," Evidence Report/Technology Assessment, no. 151, pp. 1-115, 2007.
[30] D. M. Picone, M. G. Titler, J. Dochterman et al., "Predictors of medication errors among elderly hospitalized patients," American Journal of Medical Quality, vol. 23, no. 2, pp. 115127,2008 . 


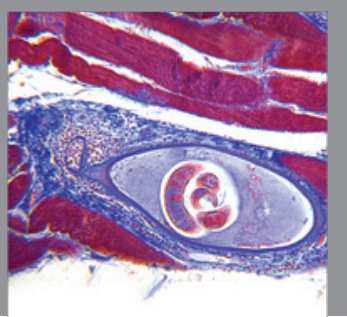

Gastroenterology

Research and Practice
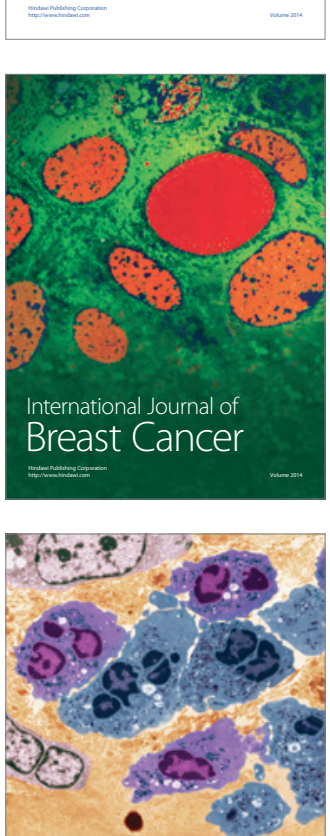

International Journal of Inflammation
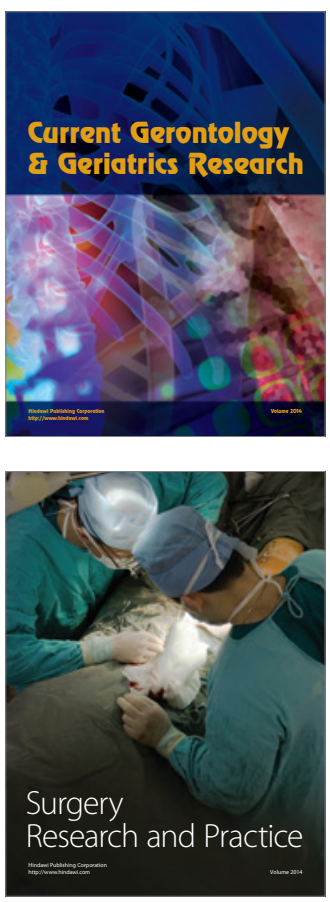
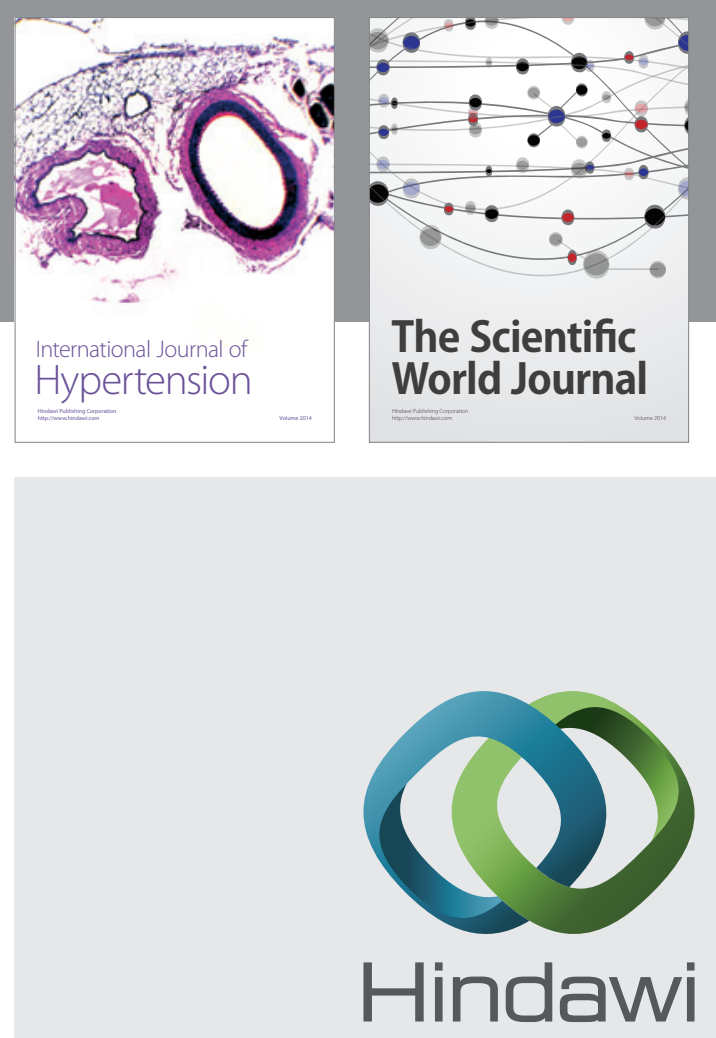

Submit your manuscripts at

http://www.hindawi.com
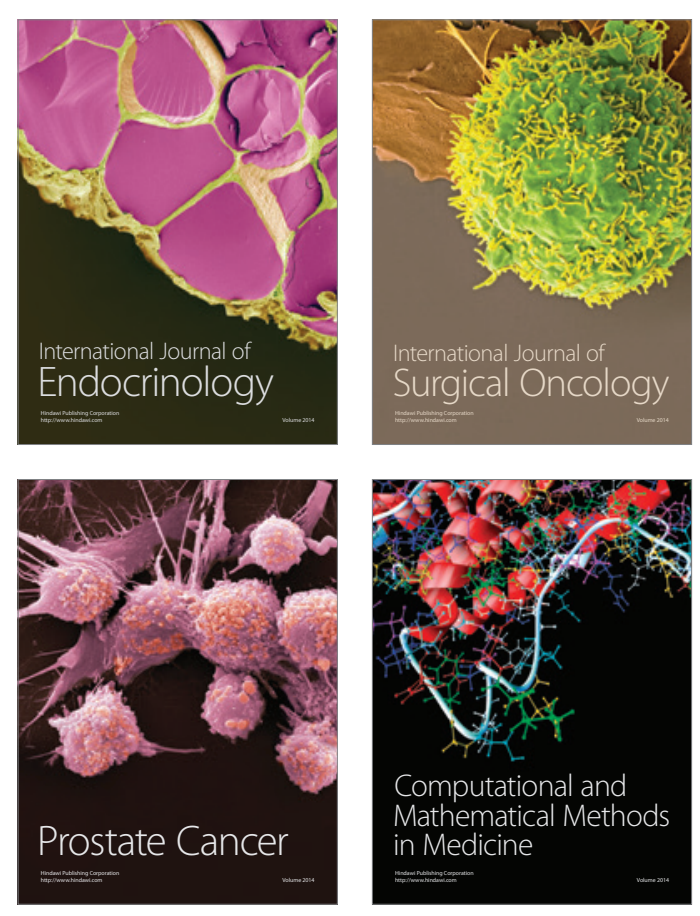
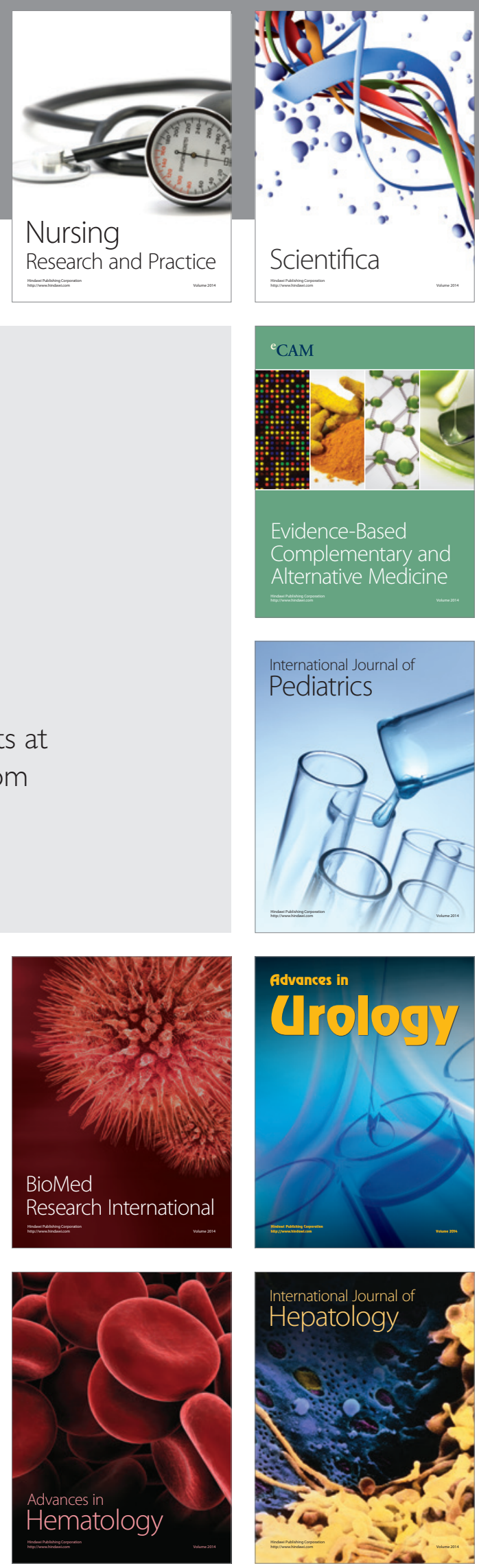